\title{
Plasmocytoma, multiple myeloma and plasma cell neoplasms in orofacial region
}

\author{
Zajko J, Czako L, Galis B \\ Department of Oral and Maxillofacial Surgery, Faculty of Medicine, Comenius University and University Hospital, \\ Bratislava, Slovakia. zajko.juraj@gmail.com
}

\section{ABSTRACT}

A neoplastic proliferation of B cell lymphocyte is called plasma cell neoplasms, results from malignant plasma cells transformation in bone marrow. The authors present a clinical study and overview of this pathology in maxillofacial region for six years (Tab. 2, Ref. 14). Text in PDF www.elis.sk.

KEY WORDS: plasma cell neoplasms, multiple myeloma, solitary plasmocytoma, extramedulary plasmocytoma, temporomandibular joint, lymphatic system, submandibular gland.

\section{Introduction}

Plasmocytoma is a rare malignant tumour of differentiated B-cells in bone marrow. A neoplastic proliferation of B cell lymphocyte is called plasma cell neoplasms. They are divided into three types. Solitary plasmocytoma of bone (SPB), extramedulary plasmocytoma (EMP) and disseminated form also called multiple myeloma (MM). The incidence ratio SPB : EMP : MM is approximately $2: 1: 40$. The most common sites of SPB are vertebral bodies, ribs or the pelvis, whereas the lower jaw is reported to be involved in only $3-5 \%(1,2)$. EMP is typically presented as a well-localized submucosal mass or swelling, sometimes with polypoidal configuration, EMP occurs in the upper aerodigestive tract in more than $90 \%$ of patients, most often in the nasal cavity, paranasal sinuses, nasopharynx, tonsils and larynx $(7,13)$. Multiple myeloma (MM) is the disseminated type of this disorder. It accounts for $1 \%$ of all types of malignancies and slightly more than 3-5\% of plasma cell neoplasms. The term of multiple myeloma was coined by von Rustizky in 1873 . It develops mainly in men aged $50-70$ years, with a mean age of 60 years. Less than $3 \%$ of cases are diagnosed in people younger than 40 . The male - female ratio is $3: 1$. The occurrence in the jaw bones is very common however oral lesions rarely appear with primary manifestation of the disease. Multiple myeloma is the most common primary bone cancer. Diagnosis of MM is established by histologic examination, in conjunction with clinical and radiographic data. According to the literature, $36-85 \%$ of patients with SPB may develop MM $(2,6,12,13)$.

Department of Oral and Maxillofacial Surgery, Faculty of Medicine, Comenius University and University Hospital, Bratislava, Slovakia

Address for correspondence: J. Zajko, MD, PhD, Department of Oral and Maxillofacial Surgery, Faculty of Medicine, Comenius University and University Hospital, Ruzinovska 6, SK-826 06 Bratislava, Slovakia. Phone: +421.2 .48234693$
The risk factors for multiple myeloma are not conclusive, because the cause of multiple myeloma is not known. Researchers believe that multiple myeloma is most likely the result of many risk factors acting together and may be associated with a decline in the immune system, age, specific occupations, exposure to certain chemicals (pesticides, dioxins), HIV infections and exposure to radiation $(1,4)$.

Nearly 230000 people worldwide are living with multiple myeloma, and 110000 new cases are diagnosed annually in the United States. It occurs in about 20,000 people each year. Multiple myeloma is responsible for the deaths of 10,000 Americans each year. In Czech Republic they are 1500 cases per year. The crude incidence rate shows that there are 3-4 new myeloma cases for every 100,000 males and females in Slovakia $(2,12,13,14)$.

The basic diagnosis of plasmocytoma is non-specific. It is established by immunohistochemical examination from the ostelytic bone area, in conjunction with clinical and radiographic data. More frequent clinical manifestations are persistent pain in bone, especially in the affected areas, a history of recurrent infection, fever, fatigue, hematological alterations, nephropathy and temporal arteritis. More than $30 \%$ of patients with MM develop osteolytic lesions in the jaw. In the maxillofacial region these lesions are more frequent in the posterior region of the mandible and the pain in the maxillaries may be the initial symptom of the disease $(8,9)$. Manifestations such as gingival hemorrhage, odontalgia, paresthesias, dental mobility, ulcerations and increased calcium levels in serum may also be present (7).

The diagnosis of plasmocytoma uses a wide range of interdisciplinary techniques including serum protein electrophoresis, bone marrow biopsy, urine analysis for Bence Jones protein and complete blood count, plain film radiography, MRI and PET-CT. The X-ray and laboratory findings in a case of plasmocytoma in bone are very similar to those of multiple myeloma. Calcium level in bone form of this disease may be increased. The most important need is for careful investigation to confirm that there is only one 
tumour present. If the tumour is outside the bone the laboratory tests will again be similar to those for myeloma but special X-ray investigations may be necessary to determine the exact boundaries of the tumour before radiotherapy can be given (10). Like myeloma, solitary plasmacytomas often produce an abnormal protein and the disappearance of this protein can be used to check on the success of treatment and to screen for any reappearance of the disease $(6,10,11,14)$.

\section{Materials and methods}

Our evaluation was based on the occurrence of a rare form of solitary plasmocytoma of the temporomandibular joint (TMJ) region of the mandible. This clinical study aimed to report the characteristics and treatment outcome of 4 patients, one with solitary plasmocytoma of bone and three extramedullary plasmocytomas (lymphatic nodes and submandibular salivary gland, buccal region, parotideal gland) of the head and neck region treated at the Department of oral and maxillofacial surgery, Comenius University, Bratislava between years 2009-2014.

During the primary investigations, our working diagnoses were recorded as tumors like lesions without any clinical signs and symptoms of plasma cell neoplasms. All 4 patients underwent preoperative physical examinations without diagnosis of plasmocytoma. In all 4 cases the patients have good condition and general health status before the surgical treatment, and report just a local problem with tumour mass. Postoperatively, the histologic and immunohistochemical examination of markers and serum free light-chains CD20-, CD138+, CD56-, CD38+, Ka, La+ from the ostelytic bone area and soft tissue masses confirm a final diagnosis of plasmocytoma.

\section{Results}

We diagnosed a total of 4 patients with plasmocytoma of head and neck region within six years. 2 women and 2 men with the median age of 58 (range 45-66) years (Tab. 1). One patient with solitary plasmocytoma of the TMJ region, three patients with extramedulary plasmocytoma. One in the submandibular region to lymphatic nodes and submandibular salivary gland, one in the cheek to buccal region and one patient with plasmocytoma of the parotideal gland. The disease in two patients was recorded as the primary process (Tab. 2). Another one was recorded with disseminated process to long bones and vertebrae, into the lung, head and neck. In one patient with a primary diagnosis of epidermoid carcinoma the lymph nodes showed small cell B-NHL spectrum of B-CLL / SLL B-variant with plasmocytoid differentiation (Ka + ), ZAP-70-neg. All patients were consulted at the Department
Tab. 2. The disease in two patients was recorded as the primary process.

\begin{tabular}{ll}
\hline No & Histological conclusion \\
\hline 1 & Mature Plasmocytoma of the mandible with medullary origin \\
\hline 2 & Extramedullary plasmacytoma with malignant proliferation \\
\hline 3 & Plasmocyte malignant proliferation of a shift to blast proliferation \\
\hline 4 & $\begin{array}{l}\text { Lip cancer and LN with the image of B NHL with plasmocytoid } \\
\text { differentiation. }\end{array}$ \\
\hline
\end{tabular}

of Oncology and accepted for treatment with chemotherapy and supportive care. All four patients underwent radical surgery plus postoperative irradiation/chemotherapy for plasmacytoma. Three patients were finally diagnosed with dissemination of the disease to vertebral bodies and ribs and to the orofacial region. Progressive multiple myeloma was confirmed by standard procedures, such as identification of new lytic bone lesions, marrow plasmacytosis, or rising myeloma protein level. Chemotherapy for multiple myeloma was given in accordance with specific protocols at the Oncological Clinic of St. Elisabeth, Bratislava. Radiotherapy with or without surgery gives the best local and regional control. One patient developed recurrence in the TMJ region following radical surgery and radiotherapy. One patient died in 36 month follow up period. Two patients underwent autologous bone marrow transplantation.

\section{Discussion}

Plasma cells, also called plasma B cells plasmocytes are white blood cells that secrete large volumes of antibodies. They are transported by the blood plasma and the lymphatic system. Plasmocytes originate from bone marrow. Plasma cells produce specific immunoglobulins, which are commonly called antibodies. A neoplastic proliferation of B cell lymphocyte is called plasma cell neoplasms. Abnormal clonal proliferation of plasma cells, typically in MM produce a myeloma protein - paraprotein $(3,5)$. It is an abnormal immunoglobulin fragment or immunoglobulin light chain, which can be detected in urine by electrophoresis. In some cases serum free light-chain measurement can detect free light chains in the blood. Monoclonal free light chains in the serum or urine are called Bence Jones proteins. These paraproteins do not play a role in mechanisms of immune system.

Multiple myeloma presents in the disseminated form, affecting several bones (vertebral bodies, ribs, calvarium bone, pelvis) (1, $2,4)$. Its occurrence in the jaw is common and frequently occurs in the advanced stage of the disease.

The mean tumor size in literature sources was 3 (range 2-6) $\mathrm{cm}$. Pain $(75 \%)$ and neck mass $(25 \%)$ were the most common presentations. After a median follow-up of 32 (range 12-62) months for surviving patients, the estimated 5-year survival of our patients was $75 \%$.

Tab. 1. Patients with plasmocytoma of head and neck region within six years.

\begin{tabular}{lccccc}
\hline No & gender & age & year of birth & hospitalization & Diagnosis \\
\hline 1 & M & 45 & 1965 & 2010 & Tumour of region TMJ left site \\
2 & F & 60 & 1953 & 2013 & Tumour of gl. parotis right site \\
3 & F & 60 & 1954 & 2014 & Tumour of cheek left site \\
4 & M & 66 & 1948 & 2014 & Tumour of lip with metastasis to neck \\
\hline
\end{tabular}


The etiology of plasmocytoma still remains unknown, age, viruses, chronic stimulation, high-dose irradiation and gene interactions in the reticuloendothelial system have been suggested as etiological factors. In literature to control the local disease, radiotherapy combined with or without surgery has been effective (4). Spontaneous regression is defined as complete or partial disappearance of a malignant tumour in the absence of treatment. The mechanisms of spontaneous regression are not fully understood but they are proposed to include immune mediation, tumour inhibition by growth factors and cytokines, angiogenesis inhibition and apoptosis. Regression often appears to follow some non-specific mechanical event, such as partial tumor resection, incomplete excision or biopsy. Additional events that have been associated with regression are local infection, autoimmune illness, irradiation of metastases other than those that regress, transfusion reaction and pregnancy termination $(5,8)$.

Initial clinical signs and symptoms of solitary plasmocytoma of bone should be pain, pathological fracture, spinal cord compression. Extramedullary plasmocytoma can occur at any site, but $80-90 \%$ of extramedullary plasmocytomas are in the head and neck area, particularly within the upper airways and oral cavity. Symptoms may include: swelling or a mass, headache, nasal discharge, nose bleeds, nasal obstruction, sore throat, hoarseness, difficulty talking (dysphonia), difficulty swallowing (dysphagia), stomach pain, breathlessness (dyspnoea), coughing up blood (haemoptysis). Cutaneous/skin involvement is very rare, accounting for $2-4 \%$ of all extramedullary plasmacytomas. They typically present as red nodules or dome shaped plaques, and may ulcerate. Basic diagnostic evaluation includes history, physical examination, complete blood count, whole skeletal radiographic survey, serum and urine protein electrophoresis and immunofixation, quantitative immunoglobulin levels, urinary protein excretion in 24 hours, in addition to bone marrow aspiration and biopsy, CT, PET CT and MRI examination. ALL our patients had biochemical negative examination. Disease has to be confirmed histologicaly. Treatment is challenging with an unclear prognosis.

\section{Conclusion}

Incidence of tumors of plasma cells is possible in the maxillofacial region. Patients with diagnosed plasmacytoma were oncologically examined and classified as myeloma multiplex IgA lambda, stage III according to ISS classification. The treatment consisted of chemotherapy (Vincristine, Adriamycin, Doxorubicin) and supportive oncologic therapy dexamethasone and pamidronic acid. Control laboratory findings were within normal limits. Two patients underwent bone marrow transplantation. One patient had relapse in the area of the primary surgical site two years after surgery. Regression was reached after transplantation of bone marrow of the patient's brother. However, unlike in literature sources (5) on plasmocytoma after surgery, tumor spontaneously regressed, in our patient a new relapse started after bone marrow transplan- tation. After 6 months the process started slowly to decrease. In 2014 the patient started to suffer from colitis and died during the treatment. Another patient treated for multiple myeloma localized in the thigh, hip joint and sternum presented with spreading of the process into cheek and mandible. Biopsy confirmed plasmacytic infiltration with high tendency to plasmablastic proliferation. Also osteolytic lesions in vertebrae, anemia, thrombocytopenia, splenomegaly a tumorous expansion in pancreas were confirmed. Two patients who presented with extramedullary plasmocytoma were sent for further oncologic therapy. However, in spite of improved diagnostic options and progress in oncologic treatment, the prognosis of plasmocytoma remains unfavorable.

\section{References}

1. Adam Z, Maisnar V. Mnohočetný myelóm. 2008, 73 pp.

2. Ballová V. Mnohopočetný myelóm - diagnostika a liečba pre praktického lekára. Via Pract 2007; 4 (7/8): 338-341.

3. Durie BGM, Kyle R, Beich A et al. Myeloma management guidelines. A consensus report from the scientific advisor of the international Myeloma Foundation. Hematol J 2003; 4 (6): 379-398.

4. Chao MW, Gibbs MP, Wirth A, Quong G, Guiney MJ, Liew KH. Radiotherapy in the management of solitary extramadulary plasmocytoma. Inter Med J 2005; 35: 211-215.

5. Mezine M et al. Solitary plasmocytoma: ghost tumor? Int J Oral Maxillofac Surg 2012; 41: 17-19.

6. Millesi W, Enislidis G, Lindner A, Schobel G, Ewers R, Drach J, Rath T. Solitary plasmocytoma of the mandible a combined approach for treatment and reconstruction. Int J Oral Maxillofac Surg 1997; 26: 295-298.

7. Dengra S, Sharma N, Tiwari V. Oral manifestation of multiple myeloma as plasmacytoma: A case report. J Oral Maxillofac Surg Med Pathol 2014; 26 (3): 421-423.

8. Kenan S, Ramazanoğlu M, Sofiyev SN, Onur OD. PP035: Various manifestations of multiple myeloma in the maxillofacial region: Case reports. Oral Oncol 2013; 49 (Suppl 1): S105.

9. Strojan P, Soba E, Lamovec J, Munda A. Extramedullary plasmacytoma: clinical and histopathologic study. Int J Radiat Oncol Biol Phys 2002; 53: 692-701.

10. Radocha J, Maisnar V. Solitárny kostní plazmocytom - kazuistika. Klin Biochem Metab 2007; 15 (2): 89 - 90.

11. Rodriguez-Caballero B, Sanchez-Santolino S, Garcia-MontesinosPerea B, Garcia-Reija MF, Gomez-Roman J, Saiz-Bustilo R. Mandibular solid plasmocytoma of the jaw. A case report. Med Oral Patol Oral Cir Bucal 2011; 5: p 647-650. http://www.medicinoral.com/medicinoralfree01/vl6i5p647.pdf

12. Tothová E, Kafková A. Nový pohl'ad na patofyziológiu mnohopočetného myelómu. Onkologie 2013; 8 (1): 43-46.

13. Vošmik M, Maisnar V. solitární extramadulární plazmocytom - diagnostika a léčba. Klin Biochem Metab 2007; 15 (2): 82-84.

14. Weber DM. Solitary bone and extramedullary plasmacytoma. Hematol Am Soc Hematol Educ Progr 2005; 373-376. 